\title{
A INSERÇÃO DO SETOR SIDERÚRGICO NA ECONOMIA CAPIXABA: UMA ANÁLISE DE INSUMO-PRODUTO ${ }^{1}$
}

\author{
Giani Cláudia Setto ${ }^{2}$ \\ Gutemberg H. Brasil ${ }^{3}$ \\ Wilson da Cruz Vieira ${ }^{4}$
}

Resumo - O objetivo deste trabalho foi analisar a inserção do setor siderúrgico na economia capixaba a partir de informações das tabelas de insumo-produto da economia brasileira e das contas regionais do Brasil - Espírito Santo, nos anos de 1990 e 1999. Foram elaboradas matrizes de insumo-produto para a economia capixaba (1990 e 1999) e mensurados os efeitos de choques na demanda final sobre a produção intersetorial e geração de empregos, além do cálculo de índices de ligação dos setores considerados na análise. Os resultados obtidos evidenciam a importância do setor siderúrgico para a economia capixaba, principalmente pelos elevados efeitos multiplicadores na produção intersetorial, e indicam, a partir dos índices de ligação calculados, uma crescente inserção deste setor nessa economia ao longo da década de 1990. No tocante à geração de empregos, mesmo que não tenha sido o setor mais importante, a siderurgia é ainda capaz de gerar grande número de empregos em outros setores da economia.

Palavras-chave: Siderurgia, insumo-produto, índices de ligação, Espírito Santo.

\section{Introdução}

O setor siderúrgico, pelo fato de absorver matérias-primas de outros setores e fornecer insumos para diversas indústrias, tende a apresentar fortes ligações (a montante e a jusante) com outros setores da economia. Em razão disso, os choques sofridos por esse setor (sejam de oferta ou de demanda) tendem a apresentar efeitos multiplicadores significativos sobre a economia na qual está inserido.

Recebido em 11/11/2004 Aceito em 02/02/2005

Mestre em Economia pela Universidade Federal do Espírito Santo.

Professor do Departamento de Estatística da Universidade Federal do Espírito Santo.

4 Professor do Departamento de Economia Rural da Universidade Federal de Viçosa. 
No Brasil, a indústria siderúrgica surgiu no âmbito do modelo de substituição de importações, que visava reduzir a dependência externa e impulsionar o desenvolvimento nacional. Fatores como baixo custo da mão-de-obra e abundância de minério de ferro (principal insumo da indústria siderúrgica) contribuíram para a rápida expansão dessa indústria no país, que, atualmente, segundo o IBS (2001), responde por 3\% da produção de aço bruto no mundo, sendo o maior produtor da América Latina.

Em termos de distribuição territorial, a produção siderúrgica brasileira concentra-se basicamente na região Sudeste, que é responsável por mais de $90 \%$ das produções de ferro-gusa (exceto no início dos anos 90), aço bruto e laminados. Minas Gerais destaca-se como o principal produtor destes produtos. Na década de 1990, Espírito Santo e Rio de Janeiro ampliaram suas participações relativas, em detrimento de Minas Gerais e São Paulo (Tabela 1).

Tabela 1 - Produção siderúrgica, por estado, nos anos de 1990 e 1999 $(1.000 \mathrm{t})$

\begin{tabular}{lrrrrrr}
\hline Ano/Estado & Ferro-Gusa & \multicolumn{1}{c}{ \% } & Aço Bruto & \multicolumn{1}{l}{$\%$} & Laminados & \multicolumn{1}{c}{$\%$} \\
\hline 1990 & & & & & & \\
\hline Minas Gerais & 7179 & 33.96 & 8435.4 & 41.02 & 8237 & 42.01 \\
Rio de Janeiro & 3738 & 17.68 & 4382 & 21.31 & 4342 & 22.15 \\
Espírito Santo & 2190 & 10.36 & 2269.2 & 11.03 & 2068 & 10.55 \\
São Paulo & 2818 & 13.33 & 4111.7 & 19.99 & 3542 & 18.07 \\
Outros Estados & 5216 & 24.67 & 1368.3 & 6.65 & 1416 & 7.22 \\
\hline Total & 21141 & 100.00 & 20566.6 & 100.00 & 19605 & 100.00 \\
\hline 1999 & & & & & & \\
\hline Minas Gerais & 12535.1 & 51.39 & 8660.5 & 34.65 & 8516.3 & 35.22 \\
Rio de Janeiro & 4649.8 & 19.06 & 6357.2 & 25.43 & 6119.5 & 25.31 \\
Espírito Santo & 4731.3 & 19.40 & 4762.7 & 19.05 & 4643.6 & 19.20 \\
São Paulo & 2476.7 & 10.15 & 3697.3 & 14.79 & 3489.9 & 14.43 \\
Outros Estados & 0 & 0.00 & 1517.9 & 6.07 & 1410 & 5.83 \\
\hline Total & 24392.9 & 100.00 & 24995.6 & 100.00 & 24179.3 & 100.00 \\
\hline Fonte: IBS(1999)
\end{tabular}

Fonte: IBS (1999) e informações enviadas, via fax, pelo IBS. 
Desde seu surgimento, a indústria siderúrgica nacional tem passado por fases distintas. Na primeira, intensificada na década de 70, houve expansão de sua capacidade produtiva e melhoria tecnológica. Entretanto, esse desenvolvimento foi comprometido, na década de 80 , pelos problemas de ajuste externo, e o setor siderúrgico, com alta participação estatal, precisou passar por um processo de reestruturação que envolveu aquisições, fusões e privatizações.

A privatização do parque siderúrgico nacional teve início em 1988 e intensificou-se nos anos de 1991 a 1993, mediante Programa Nacional de Desestatização (PND) (BNDES, 2001). Dado que dificilmente o Estado cumpriria, com recursos estatais, o montante de investimentos necessários para que a siderurgia nacional mantivesse níveis adequados de competitividade, a privatização pode ser considerada um marco inicial de um nova fase desse setor na economia nacional.

No Espírito Santo, estado em que a participação relativa do setor siderúrgico mais cresceu na década de 1990 (Tabela 1), a principal empresa deste setor, Companhia Siderúrgica de Tubarão (CST), foi privatizada em 1992. Com a privatização, essa empresa pôs em prática um ambicioso plano de crescimento e modernização, com elevados investimentos. No período 1993/1995, foram investidos US\$ 373 milhões para viabilizar a produção de placas de aço, reduzir custos e melhorar a competitividade da Companhia no mercado internacional (CST, 1998).

Na segunda fase, concluída em 1998, foram investidos US\$ 900 milhões, com o objetivo principal de expandir a capacidade de produção da Companhia e aprimorar a qualidade de seus produtos. Mais recentemente, com inversões previstas de US\$ 500 milhões, a Companhia pretende diversificar sua produção e considerar projetos de melhorias operacionais e de proteção ambiental (CST, 1997 e 2000). Todos esses investimentos, certamente, têm proporcionado efeitos significativos na economia capixaba, pois a siderurgia é uma das principais indústrias deste estado. 
Este trabalho teve o objetivo geral de analisar a inserção do setor siderúrgico na economia capixaba, a partir de informações das tabelas de insumo-produto da economia brasileira (Tabelas de Recursos e Usos) e das contas regionais do Brasil - Espírito Santo, nos anos de 1990 e 1999.

Os objetivos específicos foram:

a) Estimar as demandas finais por atividade da economia capixaba, nos anos de 1990 e 1999 ;

b) Elaborar matrizes de insumo-produto da economia capixaba, referentes a esses dois anos;

c) Mensurar os efeitos de choques na demanda final sobre a produção intersetorial e geração de emprego, a partir das matrizes de insumoproduto geradas; e

d) Calcular índices de ligação (para frente e para trás) dos setores considerados nas matrizes de insumo-produto geradas.

\section{Metodologia}

\subsection{Modelo analítico}

Neste trabalho utilizou-se, como instrumental analítico, um modelo de insumo-produto do tipo Leontief. Este modelo é uma adaptação da teoria neoclássica de equilíbrio geral para o estudo empírico das inter-relações dos diversos setores de uma economia. Na modelagem de insumo-produto são estabelecidas relações de compra e venda intersetorial e observamse os seguintes aspectos:

a) Equilíbrio geral - há um conjunto de preços que compatibiliza as quantidades ofertadas e demandas nos diversos setores da economia; 
b) Estática comparativa - podem-se comparar diferentes situações de equilíbrio decorrentes de distúrbios (choques) impostos ao modelo; e

c) Convergência - o sistema econômico modelado converge para um novo equilíbrio após a ocorrência de algum distúrbio (choque).

Segundo Chiang (1982), o modelo de insumo-produto fundamenta-se nas seguintes hipóteses:

a) Cada indústria (atividade/setor) produz apenas um produto homogêneo;

b) Cada indústria (atividade/setor) usa uma razão fixa de insumos (combinação de fatores) para a produção de seu produto; e

a) A produção de todas as indústrias está sujeita a rendimentos constantes à escala, de tal forma que, se todas os insumos variarem na mesma proporção $k$, o produto variará exatamente nessa proporção.

I $=($ Os fyyxos.intersetoriais de bens e serviços de uma economia, determinados por fatores tecnológicos e econômicos, podem ser descritos por um sistema de equações simultâneas, da seguinte forma (Leontief, 1965):

$$
x=A x+y,
$$

em que é vetor ( $\mathrm{n} \times 1$ ) com o produto total de cada setor; , vetor ( $\mathrm{n}$ $\mathrm{x}$ 1) com a demanda final setorial; , matriz ( $\mathrm{n} \times \mathrm{n}$ ) com os coeficientes técnicos de produção; $n$, número de setores (atividades) considerado no modelo.

Neste modelo, como o vetor de demanda final setorial é conhecido e fixo, pode-se determinar o vetor de produto total setorial pela seguinte equação matricial:

em que $I$ é matriz identidade (n x n). 
Em geral, os vetores $x$ e são facilmente obtidos de estatísticas oficiais. Por outro lado, a matriz de coeficientes técnicos de produção (matriz , do modelo de insumo-produto) nem sempre está prontamente disponível. Entretanto, no caso do Brasil, pode ser obtida, indiretamente, das tabelas de insumo-produto da economia brasileira, divulgadas pelo Instituto Brasileiro de Geografia e Estatística (IBGE). Entre outras informações, esta instituição divulga duas tabelas básicas: $V$ (atividades x produtos) com dimensão (m x n) e $U$ (produtos x atividades) com dimensão (n x m), que são fundamentais para obter a matriz $A$.

De acordo com o IBGE (1989) e Vieira (1996), procedeu-se da seguinte forma para obter a matriz de coeficientes técnicos de produção (matriz ). Inicialmente, definiu-se a seguinte matriz de coeficientes técnicos (considerou-se que $\mathrm{m}=\mathrm{n}$ para efeito de simplificação das operações matriciais definidas a seguir):

em que $\hat{x}$ é vetor $x$ diagonalizado.

Das tabelas de insumo-produto da economia brasileira podem-se obter ainda os vetores (n x 1) [total da demanda final do produto] e $Q$ (n x 1) [total da demanda (intermediária e final) do produto]: $Q=U+E$ [IBGE (1989)]. ${ }^{5}$ Definiu-se, então, a matriz (n x n), cujos elementos medem a fração da produção total do bem “j” produzido pela atividade "i", da seguinte forma:

\footnotetext{
Deve ser entendido como o vetor Q é igual à soma dos elementos correspondentes das colunas da matriz U mais os elementos correspondentes da coluna do vetor $\mathrm{E}$ (identidade contábil). Não confundir com a soma da matriz U com o vetor E, o que seria uma operação matricial impossível de ser realizada.
} 


\subsection{Fontes de dados e procedimentos utilizados}

Os dados utilizados neste trabalho consistiram das tabelas de insumoproduto da economia brasileira (Tabelas de Recursos e Usos) e das Contas Regionais do Brasil - Estado do Espírito Santo, nos anos de 1990 e 1999 (disponíveis no site do IBGE - http://www.ibge.gov.br), e informações sobre o setor siderúrgico foram obtidas do Instituto Brasileiro de Siderurgia (IBS). Nesses dois anos, início e final da década de 1990, buscou-se capturar duas situações distintas: uma anterior à privatização da Companhia Siderúrgica de Tubarão (CST), que ocorreu em 1992, e outra, pós-privatização, após um período de crescimento e modernização dessa empresa.

Nas Contas Regionais do Brasil, o IBGE fornece, para cada atividade (setor) e estado da Federação, o Valor da Produção, o Consumo Intermediário e o Valor Adicionado. Essas informações, junto com a Matriz da economia brasileira, podem ser utilizadas na gerarão de matrizes de coeficientes técnicos de insumo-produto estaduais. $\mathrm{O}$ valor da produção valora os bens e serviços dos produtores mercantis, bem como os serviços das instituições privadas sem fins lucrativos, que prestam serviços às famílias, e os serviços domésticos remunerados. O consumo intermediário representa o valor dos bens e serviços consumidos no processo produtivo, e o valor adicionado é o saldo entre o valor da produção e o consumo intermediário; corresponde ao valor pago aos fatores de produção durante o processo produtivo em cada atividade econômica.

O primeiro passo na construção das matrizes de insumo-produto da economia capixaba consistiu em definir as agregações das diversas atividades e produtos das tabelas de insumo-produto da economia brasileira e das atividades das Contas Regionais do Brasil - Estado do Espírito Santo. Nota-se que as tabelas de insumo-produto da economia brasileira (Tabelas de Recursos e Usos) estão estruturadas em 43 atividades e 80 produtos. No caso das Contas Regionais do Brasil, estão definidas apenas 15 atividades. Partiu-se, então, das informações mais agregadas das Contas Regionais, pois são as únicas disponíveis em nível estadual. 
Dados os objetivos deste trabalho, foram feitas agregações de algumas atividades das Contas Regionais do Brasil - Estado do Espírito Santo. Considerou-se, neste trabalho, um total de 12 atividades. A compatibilização das atividades consideradas neste trabalho e das Contas Regionais do Brasil com tabelas de insumo-produto da economia brasileira (Tabelas de Recursos e Usos) é mostrada na Tabela 2.

Tabela 2 - Compatibilização das informações das Contas Regionais com Tabelas de Recursos e Usos da economia brasileira

\begin{tabular}{lll}
\hline Atividade & Contas Regionais & Tabelas de Recursos e Usos \\
\hline 1. Agropecuária & Agropecuária & Atividade 01(**) \\
2. Mineração & Ind. Extrativa Mineral & Atividades de 02 a 04 \\
3. Siderurgia(*) & Indústria de Transformação & Atividade 05 \\
4. Outras Indústrias & Indústria de Transformação & Atividades de 06 a 32 \\
5. Eletric., Gás, Água & Eletricidade, Gás e Água & Atividade 33 \\
6. Construção & Construção & Atividade 34 \\
7. Comércio & Comércio e Reparação de Veículos e outros & Atividade 35 \\
8. Transp. E Comunic. & Transp., Armazenagem e Comunicações & Atividades 36 e 37 \\
9. Interm. Financeira & Intermediação Financeira & Atividade 38 \\
10. Ativ. Imobiliárias & Ativ. Imobiliárias, Aluguéis e Outros Serviços & Atividades 40 e 41 \\
11. Adm. Pública & Adm. Pública, Defesa e Seguridade Social & Atividade 42 \\
12. Outros Serviços & Saúde, Educ. Mercantis, Aloj., Alimen. e Outros & Atividades 39 e 43 \\
\hline
\end{tabular}

Notas: (*) A atividade Siderurgia foi desagregada da Indústria de Transformação.

(**) Codificação utilizada pelo IBGE.

Após as agregações, obteve-se, ao final, uma matriz para o estado do Espírito Santo composta de 12 atividades. Nas Contas Regionais, o setor siderúrgico está agregado à atividade "Indústria de Transformação", que foi desagregada em 2 outras atividades: "Siderurgia" e "Outras Indústrias". Tomaram-se por base as informações do Instituto Brasileiro de Siderurgia (IBS) sobre produção por estados dos produtos siderúrgicos (Ver Tabela 1). De posse do valor da produção siderúrgica nacional das Tabelas de Recursos e Usos e das informações do IBS, foram consideradas, neste trabalho, as seguintes participações relativas do estado do Espírito Santo na produção siderúrgica nacional: 11\% em 1990 e 19\% em 1999. Esses percentuais, calculados sobre os valores da produção siderúrgica nacional das Tabelas de Recursos e Usos, foram ajustados 
às Contas Regionais do Brasil $^{7} \mathrm{e}$, posteriormente, rateados para o estado do Espírito Santo (Valor da Produção e Consumo Intermediário).

Definidas as agregações para as matrizes de insumo-produto de economia capixaba, o passo seguinte foi manipular as tabelas de insumo-produto da economia brasileira para obter as matrizes $D B$ 's (matrizes de coeficientes técnicos), dos anos de 1990 e 1999, conforme procedimentos definidos na seção 2.1., deste trabalho ${ }^{8}$. Obtidas essas matrizes, adotou-se, inicialmente, a hipótese de que elas representariam, adequadamente, as matrizes de coeficientes técnicos do estado do Espírito Santo. Dessa forma, utilizandose a expressão $y=(I-D B) x$, com substituição do vetor de "Valor da Produção" nacional ( ) pelo seu correspondente do estado do Espírito Santo, pode-se obter uma estimativa da "Demanda Final" da economia capixaba.

Um segundo procedimento utilizado para estimar a demanda final da economia capixaba foi considerar que esta segue o mesmo padrão da demanda final nacional ${ }^{9}$ e que seus valores foram ajustados por atividade, usando-se uma regra de três simples, pois, em termos agregados, a demanda final estadual é igual à diferença entre o valor da produção e o valor adicionado, informações disponíveis nas Contas Regionais. Nota-se que as informações, por atividade do consumo intermediário e demanda final, são fundamentais para estimar os coeficientes técnicos da economia capixaba a partir das matrizes de coeficientes técnicos da economia brasileira.

O passo seguinte para obter as matrizes de insumo-produto da economia capixaba (anos 1990 e 1999) foi utilizar um método pelo qual se ajustam os coeficientes técnicos de insumo-produto, em nível nacional (matriz

), para refletir as informações econômicas em nível estadual (no caso, as informações do estado do Espírito Santo relativas ao "Valor da Produção" e "Consumo Intermediário", que constam nas Contas Regionais, e as relativas à demanda final estimada).

Este ajuste foi necessário, pois os valores das Contas Regionais do Brasil para os vários agregados econômicos (Valor da Produção, Consumo Intermediário, etc. ) são, em geral, inferiores aos seus correspondentes nas Tabelas de Recursos e Usos. Neste ajuste utilizou-se uma regra de três simples.

8 Os valores monetários de 1990 foram corrigidos para 1999, pelo Índice de Preços por Atacado (IPA-OG), da Fundação Getúlio Vargas.

9 Procedimento semelhante foi adotado por Souza (1997), para projetar e regionalizar uma matriz de insumoproduto para o estado do Rio Grande do Sul. 
Neste trabalho, utilizou-se o método RAS para obter as matrizes de insumo-produto de economia capixaba a partir das matrizes de coeficientes técnicos do Brasil e informações das Contas Regionais do Brasil - Espírito Santo, relativas a Consumo Intermediário e Demanda Final por atividade. Este método é descrito em detalhe, por exemplo, em Miller e Blair (1985). Consiste, basicamente, em ajustar os coeficientes, linha a linha e coluna a coluna, da matriz de coeficientes técnicos, até eles refletirem fielmente as informações disponíveis em nível estadual. Trata-se de um método largamente utilizado para atualizar matrizes de insumo-produto.

De posse das matrizes de coeficientes técnicos da economia capixaba (Ver Apêndice), obtidas pelo método RAS, pôde-se atender aos demais objetivos propostos neste trabalho. As simulações referentes aos aumentos na demanda final das atividades foram obtidas pela equação $\Delta x=(I-D B)^{-1} \Delta y$, ou seja, variações exógenas na demanda final levam a impactos na produção intersetorial e, por extensão, no nível de pessoal ocupado da economia.

No caso do nível de pessoal ocupado (dados também obtidos do IBGE para $1999^{10}$ ), o impacto foi calculado ao multiplicar o vetor de variações $\Delta x$ pelo vetor de coeficientes de pessoal ocupado (número de pessoas ocupadas em cada atividade dividido pelo valor da produção desta atividade). Esses impactos foram obtidos para todas as 12 atividades consideradas neste trabalho. Na variação exógena da demanda final, considerou-se um aumento (individual), por atividade, de $\mathrm{R} \$ 100$ mil reais (valores correntes de 1999). Em seguida, avaliaram-se os impactos desse aumento (individual) na demanda final de cada atividade sobre a variação da produção intersetorial e geração de emprego na economia capixaba.

Foram calculados dois tipos de índices de ligação a partir das matrizes de insumo-produto da economia capixaba: índices de Rasmussem-

10 Não há informações sobre pessoal ocupado, em nível estadual, nas diversas atividades consideradas neste trabalho para o ano de 1990. 
Hirschman e índices puros de ligações interindustriais. Os índices de Rasmussem-Hirschman, de ligações para frente e para trás, das 12 atividades consideradas neste trabalho foram calculados a partir das seguintes expressões (Bulmer-Thomas, 1982):

Índice de ligação para frente $\left(\mathrm{T}_{\mathrm{i}}\right)$ :

Índice de ligação para trás $\left(\mathrm{T}_{\mathrm{j}}\right)$ :

$$
T_{j}=\left(\sum_{i=1}^{n} r_{i j} / n\right) /\left(\sum_{i=1}^{n} \sum_{j=1}^{n} r_{i j} / n x n\right)
$$

$r_{i j}=$ elemento da matriz $(I-A)^{-1}$ da economia capixaba.

Os índices de Rasmussem-Hirschman, assim como outros que medem as ligações para frente e para trás entre atividades (setores) de uma economia ou região, permitem identificar a importância relativa das diversas atividades/setores, ou seja, as atividades mais importantes de uma economia são aquelas cujos valores desses índices são relativamente mais elevados. No caso dos índices de Rasmussem-Hirschman, valores maiores do que 1 (um) indicam atividades/setores acima da média, ou seja, setores-chave para o crescimento da economia. 
Para o cálculo dos índices puros de ligações, a matriz de coeficientes técnicos da economia capixaba $(A)$ foi decomposta da seguinte forma para isolar a atividade/setor $j$ do resto da economia (Guilhoto et al., 1994):

em que

$A_{j j}=$ matriz de insumos diretos dentro da atividade/setor $j$;

$=$ matriz de insumos diretos dentro do resto da economia (economia menos o setor $j$ );

$=$ matriz retangular que mostra os insumos diretos adquiridos pela atividade/setor $j$ do resto da economia; e resto da economia da atividade/setor $j$.

O índice puro de ligações para trás (PBL) é definido pela seguinte expressão:

em que

$i_{r r}^{\prime}=$ vetor linha unitário de dimensão apropriada;

$\Delta_{r}=\left(I-A_{r r}\right)^{-1} ; \mathrm{e}$

$q_{j j}=$ valor da produção total na atividade/setor $j$.

O índice puro de ligações para frente (PFL) é definido pela seguinte expressão: 
em que $q_{r r}=$ vetor-coluna com volume de produção total em cada atividade/setor do resto da economia. Os demais termos já foram definidos anteriormente.

No caso dos índices puros de ligações, as atividades/setores que apresentam os maiores valores são consideradas setores-chave da economia. Cabe observar que não há um critério amplamente aceito para definição de setores-chave quando se usa este enfoque de índices de ligações.

\section{Resultados e discussão}

As estimativas da demanda final, por atividade, da economia capixaba para os anos 1990 e 1999, conforme procedimentos descritos na seção 2.2 deste trabalho, estão apresentadas na Tabela 3. Nas estimativas da demanda final das colunas DF1 (1990 e 1999), considerou-se que a economia capixaba segue o padrão nacional, enquanto nas colunas DF2 a demanda final foi estimada a partir da expressão $y=(I-D B) x$, em que é o vetor do valor de produção da economia capixaba e , matriz de coeficientes técnicos da economia nacional. 
Tabela 3 - Demandas finais estimadas, por atividade, da economia capixaba para os anos 1990 e 1999 (em milhões de reais de 1999)

\begin{tabular}{|c|c|c|c|c|c|c|}
\hline \multirow[b]{2}{*}{ Atividade } & \multicolumn{3}{|c|}{1990} & \multicolumn{3}{|c|}{1999} \\
\hline & DF1 & DF2 & $\mathrm{DF} 3$ & $\overline{\mathrm{DF} 1}$ & DF2 & $\overline{\mathrm{DF} 3}$ \\
\hline 1. Agropecuária & 488.47 & 401.94 & 403.18 & 783.15 & 700.45 & 674.14 \\
\hline 2. Mineração & 84.02 & -339.37 & 84.28 & 101.57 & -609.28 & 97.76 \\
\hline 3. Siderurgia & 71.43 & 1647.38 & 1652.45 & 92.99 & 3223.15 & 3102.08 \\
\hline 4. Outras Indústrias & 3216.03 & 1845.38 & 1851.06 & 4337.13 & 1348.42 & 1297.77 \\
\hline 5. Eletric.,Gás, Água & 145.50 & 52.33 & 52.49 & 288.78 & 73.12 & 70.37 \\
\hline 6. Construção & 1384.87 & 1790.22 & 1795.73 & 2153.32 & 2860.24 & 2752.80 \\
\hline 7. Comércio & 163.54 & 263.75 & 264.56 & 469.93 & 538.50 & 518.28 \\
\hline 8. Transp. e Comum. & 422.62 & 1062.64 & 1065.91 & 831.49 & 1866.44 & 1796.33 \\
\hline 9. Interm. Financeira & 222.38 & -48.41 & 223.06 & 314.66 & -183.65 & 302.84 \\
\hline 10. Ativ. Imobiliárias & 507.17 & 46.88 & 47.02 & 1910.34 & 1203.88 & 1158.65 \\
\hline 11. Adm. Pública & 2155.10 & 1646.30 & 1651.37 & 3287.71 & 3000.49 & 2887.78 \\
\hline 12. Outros Serviços & 995.51 & 763.19 & 765.54 & 1473.92 & 1440.29 & 1386.19 \\
\hline Total & 9856.63 & 9132.22 & 9856.63 & 16045.00 & 15462.06 & 16045.00 \\
\hline
\end{tabular}

Fonte: Dados da pesquisa.

Com base nas informações do valor da produção por atividade e características da economia capixaba, percebe-se claramente que as estimativas da demanda final, dadas por DF1 (Tabela 3), são pouco consistentes. Por um lado, o setor "Siderurgia" é o menos importante em termos de demanda final, o que não reflete a realidade da economia capixaba. Por outro, as estimativas dadas por DF2, embora consistentes, subestimam o total da demanda final da economia capixaba e duas atividades/setores apresentam valores negativos, ou seja, valores inconsistentes.

Diante desses resultados, optou-se por considerar como estimativas da demanda final da economia capixaba as colunas DF3 (Tabela 3), as quais foram geradas com base nas informações das colunas DF1 e DE2. Os valores negativos das colunas DF2 foram substituídos pelos respectivos valores positivos das colunas DF1. Com isso, o somatório das demandas 
individuais das atividades superou o total da demanda final de cada ano. Utilizou-se uma regra de três simples para ajustar os valores, de forma a obter os valores apresentados nas colunas DF3, os quais foram efetivamente utilizados nas demais estimativas apresentadas neste trabalho.

É importante salientar que as hipóteses utilizadas para estimar a demanda final da economia capixaba são altamente plausíveis, quando as economias estadual e nacional possuem estruturas econômicas muito semelhantes. Entretanto, os resultados das estimativas, apresentado na Tabela 3, mostram que há diferenças importantes entre essas duas economias, o que levou a adotar o procedimento de aproveitar informações das duas alternativas e ajustar os valores das demandas individuais, por atividade, para obter o valor total da demanda final.

Um procedimento mais trabalhoso para obter a demanda final estadual, por atividade, seria tentar estimar cada um de seus componentes (Consumo, Investimento, Gastos do Governo e Exportação), individualmente, como fizeram, por exemplo, Haddad et al. (2002). Neste caso, trabalha-se com informações de diferentes instituições e, inevitavelmente, recorre-se a algum tipo de ajuste. No caso, por exemplo, do consumo privado, esses autores estimaram uma equação para o país no período 1970-1998 e admitiram que a relação entre consumo e renda, observada para o país como um todo, seria válida para todos os estados da federação.

Com as informações disponíveis por atividade da demanda final e do consumo intermediário da economia capixaba e da matriz de coeficientes técnicos $(D B)$ da economia nacional, pôde-se aplicar o método RAS na obtenção de matrizes de coeficientes técnicos do estado do Espírito Santo, nos anos de 1990 e 1999 (Ver Apêndice). De posse dessas matrizes, estimaram-se os efeitos de choques na demanda final sobre a produção intersetorial e geração de empregos, além do cálculo dos índices de ligação para frente e para trás dos setores da economia capixaba. 
Para análise dos efeitos de choques na demanda final, estabeleceu-se um valor de R \$ 100 milhões (valores de 1999) para efeito de comparação entre as diversas atividades/setores. Este valor representa um acréscimo na demanda final em relação aos anos-base (1990 ou 1999). Em termos percentuais, o que representa esse acréscimo para cada atividade, individualmente, está na Tabela 4.

Tabela 4 - Acréscimos (em percentagem) de aumentos de R $\$ 100$ milhões (valores corrente de 1999) nas demandas finais, por atividade, na economia capixaba, nos anos de 1990 e 1999

\begin{tabular}{lrr}
\hline Atividade & 1990 & 1999 \\
\hline 1. Agropecuária & 24,80 & 14,83 \\
2. Mineração & 118,65 & 102,29 \\
3. Siderurgia & 6,05 & 3,22 \\
4. Outras Indústrias & 5,40 & 7,71 \\
5. Eletric., Gás, Água & 190,52 & 142,10 \\
6. Construção & 5,57 & 3,63 \\
7. Comércio & 37,80 & 19,29 \\
8. Transporte e Comunicação & 9,38 & 5,57 \\
9. Intermediação Financeira & 44,83 & 33,02 \\
10. Atividades Imobiliárias & 212,67 & 8,63 \\
11. Administração Pública & 6,06 & 3,46 \\
12. Outros Serviços & 13,06 & 7,21 \\
\hline
\end{tabular}

Fonte: Dados da pesquisa.

Observa-se, na Tabela 4, que a maioria dos percentuais apresentados é bastante plausível, exceto dos setores "Mineração" e "Eletricidade, Gás e Água", que superaram os $100 \%$. Nota-se que, por se estar considerando retornos constantes à escala nos sistemas produtivos da economia capixaba, o valor arbitrado (R\$ 100 milhões) poderia ser menor ou maior, que não mudaria a lógica desta análise. Um critério mais rigoroso para escolha desse valor seria considerar as capacidades ociosas de cada atividade/setor e demandas potenciais, o que exigiria mais informações nem sempre prontamente disponíveis. 
Definido o valor do choque na demanda final, o passo seguinte foi calcular seus efeitos na produção intersetorial e na geração de emprego. $\mathrm{Na}$ Tabela 5 apresentam-se os efeitos do choque (aumento) de $\mathrm{R} \$ 100$ milhões (valores correntes de 1999) na demanda final de todos os setores/ atividades, calculados individualmente, sobre a produção intersetorial da economia capixaba.

Tabela 5 - Efeitos de aumentos na demanda final sobre a produção intersetorial da economia capixaba, nos anos 1990 e 1999 (variação em milhões reais de 1999)

\begin{tabular}{|c|c|c|c|c|c|c|c|c|c|c|c|c|}
\hline$\overline{\text { Ativ }}$ & 1 & 2 & 3 & 4 & 5 & 6 & 7 & 8 & 9 & 10 & 11 & 12 \\
\hline 1. Agr & 9.11 & 2.62 & 7.57 & 15.34 & 3.31 & 6.06 & 1.48 & 5.88 & 0.05 & 1.26 & 2.04 & $\overline{6.41}$ \\
\hline 2. Mineração & 0.38 & 102.14 & 1.31 & 1.19 & 0.37 & 4.30 & 0.12 & 0.46 & 0.00 & 0.24 & 0.14 & 0.46 \\
\hline 3. Siderurgia & 1.75 & 2.44 & 153.31 & 7.63 & 1.58 & 7.16 & 0.73 & 2.83 & 0.02 & 0.77 & 0.61 & 2.37 \\
\hline 4. Outras Indústrias & 32.22 & 20.81 & 27.30 & 52.76 & 28.39 & 52.77 & 13.03 & 51.70 & 0.37 & 11.12 & 10.60 & 41.03 \\
\hline 5. Eletr., Gás,Água & 1.98 & 4.61 & 6.29 & 4.29 & 148.28 & 2.35 & 1.60 & 2.85 & 0.07 & 1.45 & 2.35 & 4.17 \\
\hline 6. Construção & 0.19 & 0.47 & 0.31 & 0.45 & 1.36 & 105.73 & 0.34 & 1.04 & 0.02 & 4.19 & 0.67 & 0.58 \\
\hline 7. Comércio & 8.97 & 15.25 & 16.52 & 27.01 & 6.07 & 14.27 & 110.20 & 10.91 & 0.10 & 2.52 & 4.97 & 8.57 \\
\hline 8. Transp. e Com. & 3.84 & 4.01 & 3.19 & 5.16 & 3.65 & 3.11 & 4.29 & 121.90 & 0.25 & 2.19 & 2.38 & 2.80 \\
\hline 9. Int. Financeira & 2.85 & 4.79 & 5.06 & 4.59 & 11.97 & 3.66 & 2.83 & 8.21 & 114.91 & 2.10 & 1.40 & 2.94 \\
\hline 10. Ativ & 2.55 & 4.41 & 2.56 & 4.19 & 9.29 & 4.79 & 4.74 & 7.23 & 0.53 & 103.19 & 7.40 & 3.58 \\
\hline 11. Adm. Pública & 0.93 & 0.82 & 0.74 & 1.37 & 1.47 & 1.36 & 0.74 & 1.64 & 0.07 & 0.54 & 101.03 & 1.05 \\
\hline 12. Outros Serviços & 1.12 & 1.61 & 1.45 & 1.68 & 3.80 & 1.93 & 1.49 & 3.86 & 0.23 & 0.99 & 4.49 & 102.12 \\
\hline otal & 175.89 & 163.97 & 225.61 & 225.66 & 219.53 & 207.49 & 141.58 & 218.50 & 116.61 & 130.57 & 138.06 & 176.08 \\
\hline Atividade/1999 & 1 & 2 & 3 & 4 & 5 & 6 & 7 & 8 & 9 & 10 & 11 & 12 \\
\hline 1. Agropecuária & 9.40 & 2.48 & 9.77 & 20.71 & 4.91 & 5.77 & 2.48 & 6.58 & 1.16 & 0.61 & 1.79 & 6.59 \\
\hline 2. $\mathrm{Mi}$ & .21 & 101.20 & 1.61 & 0.94 & 0.33 & 2.55 & 0.11 & 0.31 & 06 & 0.07 & 0.07 & 0.26 \\
\hline 3. Siderurgia & 1.21 & 1.63 & 164.15 & 7.22 & 1.60 & 4.76 & 0.82 & 2.16 & 0.35 & 0.25 & 0.38 & 1.57 \\
\hline 4. Outras Industr. & 24.53 & 14.44 & 26.98 & 51.24 & 31.33 & 37.42 & 16.31 & 43.23 & 6.70 & 3.99 & 7.23 & 29.73 \\
\hline 5. Elet.,Gás, Água & 1.77 & 4.17 & 9.35 & 5.35 & 179.60 & 2.03 & 2.03 & 2.87 & 1.21 & 0.54 & 1.73 & 3.70 \\
\hline 6. Construção & 0.20 & 0.58 & 0.59 & 0.72 & 2.35 & 108.14 & 0.48 & 1.58 & 0.41 & 1.99 & 0.65 & 0.73 \\
\hline 7. Com & 6.31 & 9.68 & 16.67 & 24.14 & 6.48 & 9.60 & 109.59 & 8.97 & 1.86 & 0.89 & 3.46 & 6.12 \\
\hline 8. Transp. e Com. & 3.20 & 3.96 & 5.30 & 7.48 & 3.71 & 3.49 & 6.23 & 117.99 & 5.12 & 1.41 & 1.98 & 3.65 \\
\hline 9. Int. Financeira & 0.21 & 0.38 & 0.63 & 0.49 & 1.08 & 0.28 & 0.30 & 0.66 & 107.77 & 0.07 & 0.12 & 0.22 \\
\hline 10. Ativ. Imobiliária & 3.21 & 5.11 & 4.88 & 7.30 & 11.87 & 6.16 & 8.44 & 9.46 & 15.02 & 102.07 & 6.54 & 4.58 \\
\hline 11. Adm. Pública & 1.13 & 0.82 & 1.19 & 2.16 & 1.77 & 1.53 & 1.15 & 1.98 & 1.48 & 0.28 & 100.78 & 1.22 \\
\hline 12. Outros Serviços & 0.49 & 0.75 & 1.17 & 1.23 & 5.73 & 0.81 & 1.19 & 2.97 & 7.20 & 0.22 & 4.53 & 101.77 \\
\hline & & & & .98 & & .55 & 3 & 377 & 3.34 & 23 & & 01 \\
\hline
\end{tabular}

Fonte: Dados da pesquisa. 
De acordo com a Tabela 5, verifica-se que os choques no setor Siderurgia estão entre os que causaram os maiores impactos na produção intersetorial, quando comparados aos mesmos choques nos demais setores da economia capixaba. No ano de 1990, os setores que proporcionaram os maiores efeitos sobre a produção intersetorial foram Outras Indústrias e Siderurgia. Em seguida (ordem decrescente), vieram os setores Eletricidade, Gás e Água; Transporte e Comunicação; e Construção. O setor que causou o menor impacto na produção foi Intermediação Financeira.

Há mudanças sutis na estrutura da economia capixaba, quando se comparam os efeitos dos choques na demanda final sobre a produção intersetorial, nos anos de 1990 e 1999 (Tabela 5). Alguns setores perderam importância relativa, enquanto outros se tornaram mais importantes. O setor Siderurgia continuou sendo o segundo mais importante em termos de impactos na produção intersetorial, perdendo, desta vez (1999), para o setor Eletricidade, Gás e Água. Nota-se que os efeitos dos choques no setor Siderurgia foram bem maiores em 1999, quando comparados aos do início da década (1990), o que certamente se deve ao crescimento deste setor na economia capixaba. Em 1999, o setor que causou o menor impacto na produção intersetorial foi a Atividade Imobiliária.

A Tabela 6 mostra os efeitos do mesmo choque ( $\mathrm{R} \$ 100$ milhões) na demanda final de todos os setores (calculados individualmente) da economia capixaba, em que a diferença é que a variável afetada passou a ser o nível de emprego em cada setor e na economia como um todo. Esses efeitos se referem apenas ao ano de 1999. 
Tabela 6 - Efeitos de aumentos na demanda final sobre a absorção de mão-de-obra na economia capixaba (geração de emprego), em 1999

Fonte: Dados da pesquisa.

Na Tabela 6, o que se visualiza é uma modificação significativa na importância do setor Siderurgia, com relação às análises anteriores. Quando a variável analisada passa a ser a geração de empregos, percebese que a Siderurgia fica atrás de setores como Comércio; Outros Serviços; Mineração; Outras Indústrias; e Intermediação Financeira. Na verdade, o Setor Siderurgia ganha apenas em geração de empregos do setor Agropecuária. Este é um resultado, de certa forma, esperado, pois a Siderurgia é uma indústria altamente intensiva em capital. Nota-se também que choques na demanda final do setor Siderurgia causam mais impactos, em geração de emprego, em outros setores do que na própria Siderurgia.

Na Tabela 7 há os índices de ligação (Rasmussen-Hirchman e puro) para frente e para trás, calculados para todas as atividades/setores da economia capixaba, nos anos de 1990 e 1999. 
Tabela 7 - Índices de Rasmussen-Hirschman e puros de ligação para frente e para trás das atividades/setores da economia capixaba, nos anos de 1990 e 1999

Fonte: Dados da pesquisa.

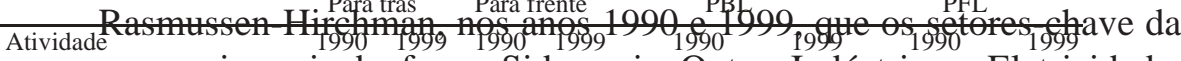

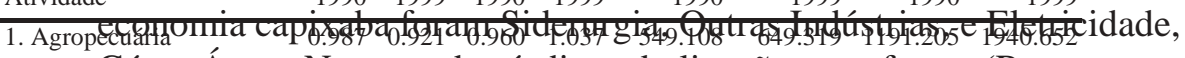

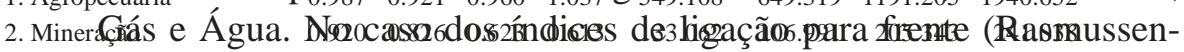

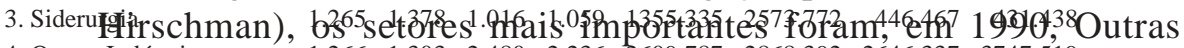

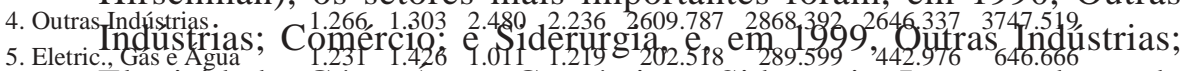

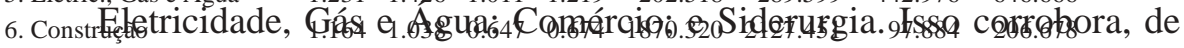

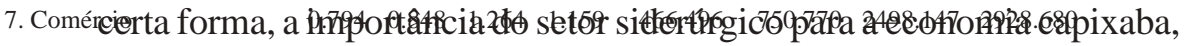

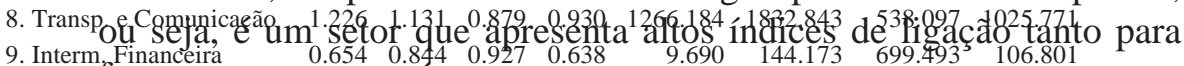

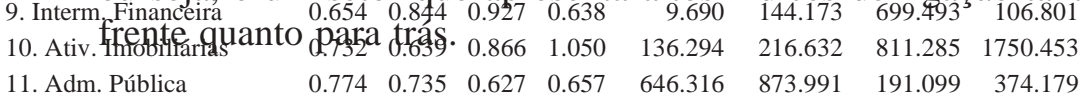

11. Adm. Pública

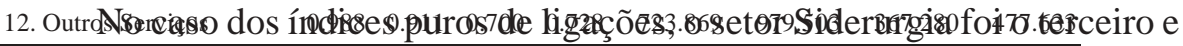
o segundo mais importante, em 1990 e 1999, respectivamente, quando são analisados os efeitos para trás. No caso dos efeitos para frente, o setor Siderurgia ocupou posições mais modestas. Um fato importante a ser destacado é que, exceto no caso dos efeitos para frente dos índices puros de ligações, todos os índices apontam, claramente, maior inserção do setor siderúrgico na economia capixaba ao longo dos anos 1990, o 
que, certamente, é um reflexo dos altos investimentos realizados nesse setor após sua privatização.

\section{Conclusões}

Neste trabalho, utilizou-se do instrumental de insumo-produto para analisar a inserção do setor siderúrgico na economia capixaba na década de 1990 . Utilizaram-se, como fonte de dados, as Tabelas de Recursos e Usos da economia brasileira, as Contas Regionais do Brasil - Espírito Santo e informações sobre produção siderúrgica, por estado, do Instituto Brasileiro de Siderurgia.

De acordo com os resultados obtidos, a Siderurgia foi um dos setores cujos choques na demanda final causaram os maiores impactos na produção intersetorial da economia capixaba. Quando a variável avaliada passa a ser a capacidade de gerar empregos, a Siderurgia perde em importância relativa, por gerar poucos empregos diretamente, pois se trata de um setor intensivo em capital. Na verdade, os efeitos de choques na demanda final do setor Siderurgia gera mais empregos em outros setores do que na própria Siderurgia.

Exceto no caso dos índices puros de ligações para frente, o setor Siderurgia está entre aqueles com maiores índices de ligações tanto para frente como para trás, o que é uma indicação de setor-chave da economia capixaba. Esses fatos corroboram as características básicas do setor siderúrgico, pois se trata de uma indústria de base (intermediária) que demanda recursos minerais e oferece produtos a uma série de setores que demandam aço e correlatos.

Os resultados deste trabalho permitem concluir que o setor siderúrgico não é apenas importante como gerador de divisas, mas é também capaz de causar efeitos significativos na economia capixaba, o que justifica políticas específicas de incentivos para esse setor. Com reflexos mais relevantes na produção do que no emprego, mas com importantes ligações 
para frente e para trás, esse setor apresenta a configuração esperada para uma importante indústria de base.

Por fim, em razão das dificuldades encontradas para obter estimativas mais precisas da demanda final, por atividade, da economia capixaba, os resultados apresentados neste trabalho devem ser avaliados com cautela. Há carência de estatísticas oficiais sobre demanda final, em nível estadual, o que dificulta o tipo de análise desenvolvido neste trabalho. Existem estatísticas oficiais sobre outros agregados, em nível estadual, tais como Valor da Produção, Consumo Intermediário e Valor Adicionado, o que já é um avanço importante.

\section{Referências bibliográficas}

BANCO NACIONAL DE DESENVOLVIMENTO ECONÔMICO E SOCIAL - BNDES. Impactos da privatização no setor siderúrgico. Brasília, 2001. 12 p.

BULMER-THOMAS, V. Input-output analysis in developing countries. New York: J. Wiley, 1982. 297p.

CHIANG, A. C. Matemática para economistas. São Paulo: McGrawHill do Brasil, 1982. 684p.

COMPANHIA SIDERÚRGICA DE TUBARÃO - CST. Relatório Anual - 1997. Vitória: CST, 1997. 25p.

COMPANHIA SIDERÚRGICA DE TUBARÃO - CST. Relatório Anual - 1998. Vitória: CST, 1998. 27p.

COMPANHIA SIDERÚRGICA DE TUBARÃO - CST. Relatório Anual - 2000. Vitória: CST, 2000. 32p.

GUILHOTO, J. J. M.; SONIS, M.; HEWINGS, G. J. D.; MARTINS, E. B. Índices de ligações e setores-chave na economia brasileira: 1959/ 
80. Pesquisa e Planejamento Econômico, vol. 24, No. 2, p.287-314, 1994.

HADDAD, E. A.; AZZONI, C. R.; DOMINGUES, E. P.; PEROBELLI, R. S. Macroeconomia dos estados e matriz interestadual de insumoproduto. Economia Aplicada, vol. 6, No. 4, Out./Dez., p.875-895, 2002.

INSTITUTO BRASILEIRO DE GEOGRAFIA E ESTATÍSTICA IBGE. Matriz de insumo-produto: Brasil - 1980. Rio de Janeiro: IBGE, 1989. v.7, 230p. (Série Relatórios Metodológicos).

INSTITUTO BRASILEIRO DE SIDERURGIA - IBS. Anuário estatístico - 1999. Rio de Janeiro, 1999. 89 p.

INSTITUTO BRASILEIRO DE SIDERURGIA - IBS. Anuário estatístico - 2001. Rio de Janeiro, 2001. 93 p.

LEONTIEF, W. Input-output economics. New York: Oxford University Press, 1965. 257p.

MILLER, R. E. \& BLAIR, P. D. Input-output analysis: foundations and extensions. New Jersey: Prentice-Hall, 1985.

SOUZA, N. J. Projeção e regionalização da matriz de insumo-produto: impacto do aumento da produção de grãos no RS e no Brasil no ano 2000. Análise Econômica, vol. 15, Março, p.110-129, 1997.

VIEIRA, W. C. Uma análise dos efeitos econômicos de estratégias de promoção de exportações. Análise Econômica, v. 14, nos. 25/26, mar./ set., 1996. p.52-62. 
Abstract: The aim of this paper was to analyze the relative importance of the steel industry to the state of Espírito Santo, Brazil. The 1990 and 1999 Brazilian inputoutput matrices and Brazil's regional accounts - state of Espírito Santo were used to build input-output matrices (1990 and 1999) to this state. Increases in final demand were simulated to analyze the effects on the production of each sector as well as on employment creation in this state. Backward and forward linkage indexes were also computed to twelve sectors with the same purpose. The results show that the steel industry is very important to the capixaba economy especially due to the high multiplier effects in response to increases in final demand. The results show also that the relative importance of the steel industry has grown during the 1990's in the capixaba economy. When compared to other sectors, the steel industry has also one the higher linkage indexes, which reinforce the relative importance of this industry to the economy analyzed.

Key words: Steel industry, input-output, linkage index, state of Espírito Santo.

\section{Apêndice}

\section{Legenda das tabelas:}

\section{1- Agropecuária}

2- Mineração

3- Siderurgia

4- Outras Indústrias

5- Eletricidade, Gás e Água

6- Construção

\section{7- Comércio}

8- Transporte e Comunicação

9- Intermediação Financeira

10- Atividades Imobiliárias

11- Administração Pública

12- Outros Serviços 
REVISTA DE ECONOMIA E AGRONEGÓCIO, VOL.3, No 1

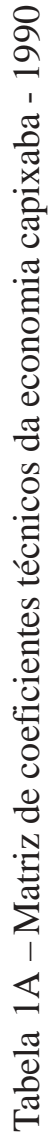

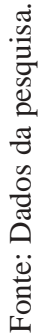


Giani Cláudia Setto, Gutemberg H. Brasil \& Wilson da Cruz Vieira

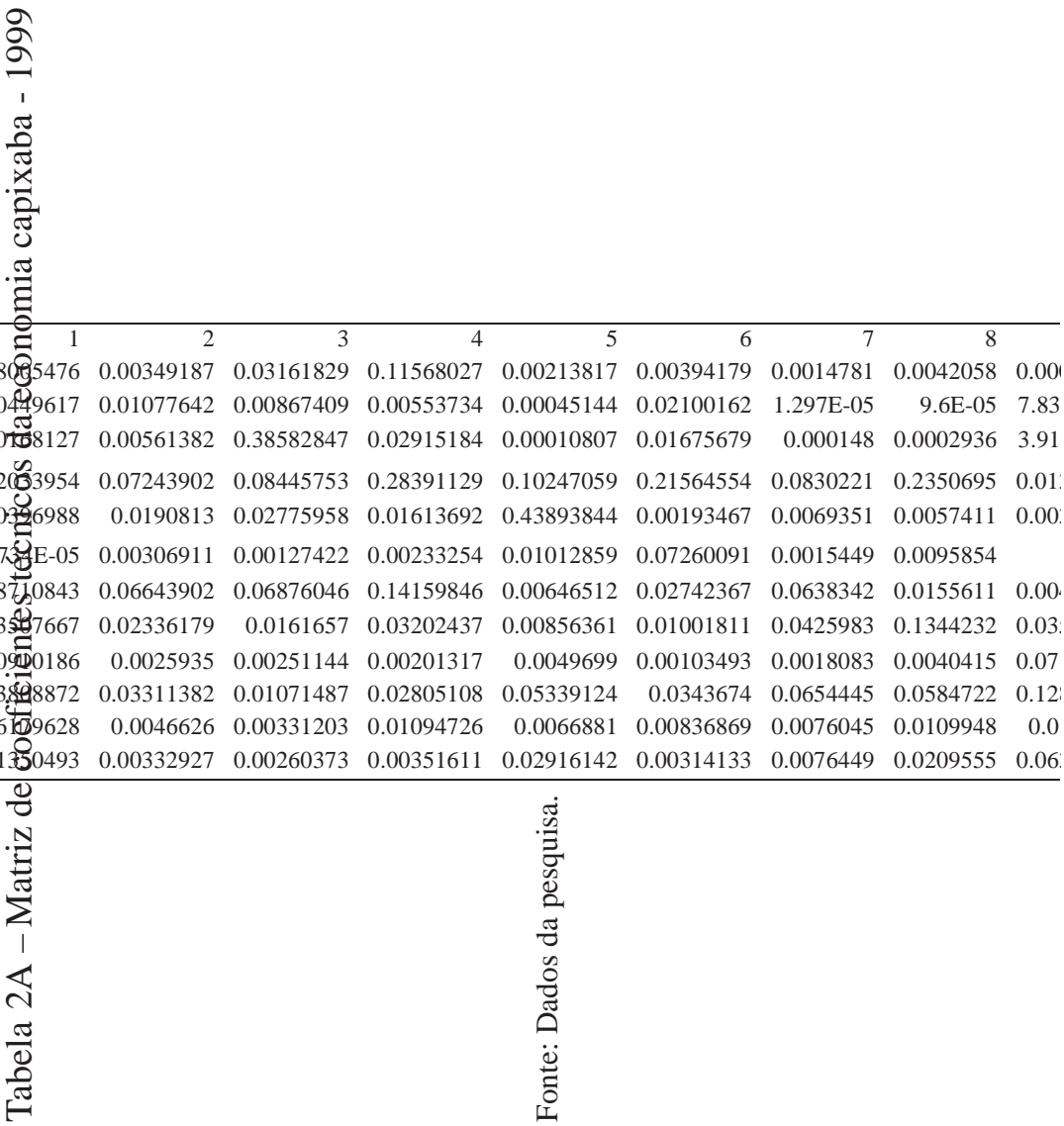


REVISTA DE ECONOMIA E AGRONEGÓCIO, VOL.3, No 1 